\title{
Steady inter and intra-annual decrease in the vocalization frequency of Antarctic blue whales
}

J. Acoust. Soc. Am. Volume 131, Issue 6, pp. 4476-4480 (2012); (5 pages)

Alexander N. Gavrilov ${ }^{1}$, Robert D. McCauley ${ }^{1}$, and Jason Gedamke ${ }^{2}$

${ }^{1}$ Centre for Marine Science and Technology, Curtin University of Technology, GPO Box U1987, Perth, Western Australia 6845, Australia

${ }^{2}$ Fisheries Ocean Acoustics Program, Office of Science and Technology, NOAA, 1315 East-West Highway, Silver Spring, Maryland 20910

\begin{tabular}{|l|l|l|l|l|}
\hline Abstract & References (14) & Article Objects (6) & Related Content & Alerts \\
\hline
\end{tabular}

Full Text: Read Online (HTML) | Download PDF | View Cart

Time averaged narrow-band noise near $27 \mathrm{~Hz}$ produced by vocalizations of many distant Antarctic blue whales intensifies seasonally from early February to late October in the ocean off Australia's South West. Spectral characteristics of long term patterns in this noise band were analyzed using ambient noise data collected at the Comprehensive Nuclear-TestBan Treaty hydroacoustic station off Cape Leeuwin, Western Australia over 2002-2010. Within 7 day averaged noise spectra derived from 4096-point FFT ( $0.06 \mathrm{~Hz}$ frequency resolution), the $-3-\mathrm{dB}$ width of the spectral peak from the upper tone of Antarctic blue whale vocalization was about $0.5 \mathrm{~Hz}$. The spectral frequency peak of this tonal call was regularly but not gradually decreasing over the 9 years of observation from $27.7 \mathrm{~Hz}$ in 2002 to $26.6 \mathrm{~Hz}$ in 2010. The average frequency peak steadily decreased at a greater rate within a season at $0.4-0.5 \mathrm{~Hz} /$ season but then in the next year recovered to approximately the mean value of the previous season. A regression analysis showed that the interannual decrease rate of the peak frequency of the upper tonal call was $0.135 \pm 0.003 \mathrm{~Hz} /$ year over $2002-2010\left(R^{2} \approx 0.99\right)$. Possible causes of such a decline in the whale vocalization frequency are considered.

(c) 2012 Acoustical Society of America

\section{ACKNOWLEDGMENT}

The authors thank Dr. David Jepsen of Geoscience Australia, who provided acoustic data from the HA01 CTBT hydroacoustic station mainly used for the study presented in this paper.

\section{Article Outline}
I. INTRODUCTION
II. DATA COLLECTION AND PROCESSING
III. RESULTS
A. Individual calls
B. Noise from whale calls

IV. CONCLUDING REMARKS

\section{RELATED DATABASES \\ Web of Science \\ View this record in Web of Science \\ View Web of Science related articles \\ KEYWORDS, PACS, and IPC \\ Keywords \\ acoustic noise, acoustic variables measurement, \\ bioacoustics, biocommunications, regression analysis, underwater sound}

\section{PACS}

43.30.Sf

Acoustical detection of marine life; passive and active

43.80.Ka

Sound production by animals: mechanisms,

characteristics, populations, biosonar

\subsection{0. $\mathrm{Nb}$}

Noise in water; generation mechanisms and

characteristics of the field

\section{International Patent Classification (I PC)}

\section{- $\mathrm{G} 01 \mathrm{H}$}

Measurement of mechanical vibrations or ultrasonic, sonic or infrasonic waves

\section{- G10K11/00}

Methods or devices for transmitting, conducting or directing sound in general; Methods or devices for protecting against, or for damping, noise or other acoustic waves in general

\section{ARTICLE DATA}

\section{History}

Received 08 Sep 2011

Accepted 26 Mar 2012

Revised 18 Mar 2012 


\section{Digital Object I dentifier}

http://dx.doi.org/10.1121/1.4707425

\section{PUBLICATION DATA}

ISSN

0001-4966 (print)

Publisher

Acoustical Society of America crossef Member $_{\text {. }}$

Your Recent History

\section{Recently Viewed}

- Steady inter and intra-annual decrease in the vocalization frequency of Antarctic blue whales

| Home || Publications || Meetings || Contact ASA || Site Map || Back to Top

Copyright @ 2013 Acoustical Society of America 